\title{
Water and Latrine Services and Associated Factors among Residents of Negele Town, Southeast Ethiopia: A Cross-Sectional Study
}

\author{
Diriba Temesgen Dagaga ${ }^{1}{ }^{1}$ and Girma Deboch Geleta ${ }^{2}{ }^{2}$ \\ ${ }^{1}$ Madda Walabu University, College of Natural and Computational Sciences, Department of Biology, P. O. Box 247, \\ Bale Robe, Ethiopia \\ ${ }^{2}$ Negele College Preparatory High School, Negele Town, Ethiopia
}

Correspondence should be addressed to Diriba Temesgen Dagaga; direteme@gmail.com

Received 9 October 2021; Revised 22 December 2021; Accepted 31 December 2021; Published 25 January 2022

Academic Editor: Issam A. Al-Khatib

Copyright ( 12022 Diriba Temesgen Dagaga and Girma Deboch Geleta. This is an open access article distributed under the Creative Commons Attribution License, which permits unrestricted use, distribution, and reproduction in any medium, provided the original work is properly cited.

\begin{abstract}
Background. Access to at least a basic water service, improved sanitation, and hygiene contribute to the human health and socioeconomic development of a country. This study was conducted to assess the water and latrine service coverage and related factors among dwellers of Negele town, southeast Ethiopia. Method. Two Kebeles (small administrative units) were randomly selected from each of the three zones of the town to collect data via questionnaires from randomly selected household heads (380), interviews of purposely selected key informants (40), and personal observations employing a cross-sectional survey design from March to May 2018. A Chi-square test was conducted to examine the association between various demographic factors and having latrine/tap water. Result. Latrine coverage of the town was low (45\%) mainly due to shortage of land or funds and expansion of illegal houses. The available latrines were poor in hygiene. Water service (solely tap water) coverage was very low (7.6\%) as a result of deficient water sources and nonfunctioning pipelines. The zones, age, educational status, marital status, and family size of the participants were statistically significantly associated with having latrine or tap water, $p<0.05$. The administration of the town has planned to build four public toilets and raise its water supply coverage to about $70 \%$ by $2019 / 2020$. Conclusion. Coverage of latrine and water services of Negele town were so low, implying that it is not on track to achieve the United Nations (UN) sustainable development goal target 6.1 and 6.2. The administration of the town should provide land to residents and search for fund sources for the construction of standardized private and public toilets. Utilizing various water sources, maintaining nonfunctional, and constructing new pipelines should be promoted to improve the water service coverage of the town targeting the national and UN sustainable development goals.
\end{abstract}

\section{Background}

Access to potable water and sanitation facilities like latrines is a basic human right and is related to social and psychological well-being, public health, socioeconomic development, and environmental sustainability [1]. However, millions of people living in developing countries lack access to such facilities due to fast population growth, poor service provision, and poor economic and educational status. They are conditioned to practice open defecation, expend much time and energy in fetching water, and tend to suffer from and die of a wide range of preventable diseases. Recognizing these, the United
Nations [2] set the sustainable development goal target 6.1 (universal access to safe water) and 6.2 (universal access to sanitation) by 2030 .

Although the country should work to achieve the United Nations development goals, open defecation has been commonly practiced throughout Ethiopia, for instance, by 28 million people in 2015, due to lack of hygiene awareness, adequate policy, and income [3]. Although the information is lacking at regional level in many cases and the national magnitude varies in different reports, the national estimated coverage of basic drinking water and basic sanitation in Ethiopia was $41 \%$ and $7 \%$, respectively, in 2017 [4]. This 
showed that the country had not achieved the targeted 100\% improved hygiene and sanitation coverage by 2015 and the country was not on the correct track to successfully extend safe water supply to $98 \%$ rural and $100 \%$ urban dwellers by 2020 via Water, sanitation, and hygiene (WASH) program [5]. Open defecation and lack of access to safe water have likely contributed to the wide prevalence of common waterborne diseases, and some recently emerged life-threatening Acute Watery Diarrhea $(48,814$ cases and 880 deaths in 2017) and cholera (6,578 cases and 56 deaths in 2017) as described by WHO [6] and Tesfay and Biru [7]), respectively, across the country.

As a developing country, Ethiopia has experienced rapid urban expansion while water and sanitary services are insufficient in many cases. Water and sanitary service coverage of an area need to be determined via scientific inquiry as they have environmental and population health risk implications and serve as an input to take appropriate measures. Such studies have been conducted in some parts of Ethiopia. Awoke and Muche [8] reported a 58.4\% latrine coverage in Bahir Dar Zuria District, northwestern Ethiopia. Admassie and Debebe [9] indicated that about $68 \%$ and $95 \%$ of inhabitants of Wolaita Sodo Town (southern Ethiopia) had access to improved water supply and latrines, respectively. According to WASH [10], 31.2\% of participants of Gonji Kolela Woreda in West Gojjam Zone, northwestern Ethiopia, were using either river or unprotected springs for their home consumption. Tesema [11] reported possession of latrines by $89 \%$ of households in Diretiyara, eastern Ethiopia. Similarly, Dagnew et al. [12] reported latrine coverage of 27.5\% for Chiro Zuria District, eastern Ethiopia. These studies covered limited areas of the country with greatly varied results, implying the need to expand the study to other regions to get dependable information on water and sanitary service coverage of the regions and that of the country as a whole. Research based information can assist to develop appropriate policies to improve water and sanitary service coverage.

This study was conducted at Negele town, southeast Ethiopia. Our preliminary survey indicated that a portion of its residents have access to latrines and water service, whereas others practice open defecation and use unsafe water sources. However, a good estimation of the number residents of the town that have access to latrine and water service was absent due to the lack of previous studies at the town. This can affect the effectiveness of plan and policy that the administration of the town may develop to improve the coverage of water and sanitation services. Thus, the study was initiated to provide baseline data on latrine and water service coverage and associated factors of the town for improvement by relevant authorities to achieve the national and UN (United Nations) goals concerning access to safe water and sanitation.

\section{Methods}

2.1. Description of the Study Area. This research was conducted at Negele town, located in Guna district, Arsi zone, Oromia region, southeast Ethiopia $\left(7^{\circ} 21^{\prime} \mathrm{N} ; 38^{\circ} 42^{\prime} \mathrm{E}\right)$. The town was established on a landscape of 300 hectares in 1984. It is located $204 \mathrm{~km}$ away from Addis Ababa, the capital city of Ethiopia. Negele town experiences a mild climate with mean annual temperature and rainfall ranging from 12 to $23^{\circ} \mathrm{C}$ and $700-1300 \mathrm{~mm}$, respectively. The town has been administered at the municipality level since 2000 and has its administrative structure led by a mayor. The administration of the town estimated its population to be 22,578 in 2017 . The town is demarcated by different rural "Kebeles" (the lowest administrative unit in Ethiopia): Amuma-Arago in the east, Nano Jawi in the west, Nano Hecho in the north, and Cire Anole in the south. It has a primary school, a secondary school, and a health center. The economic activity of its surrounding population is predominantly agriculture, comprising farming and cattle breeding.

2.2. Study Design and Population Sampling. A communitybased cross-sectional qualitative and quantitative descriptive survey was conducted at Negele town from March 24 to May 31,2018 . The town is divided into three sub-administrative zones: Central zone (Central Hindy, Center of town, and Central villages), Eastern zone (Najate, Sheep site, and East Hindy villages), and Western zone (Western Hindy, Mosque area, and Secondary school area villages). During the study, there were 4095 households; 2631 and 1464 represented by males and females, respectively, as family heads that lead a family, take major social responsibilities, and make decisions about the family. The study targeted 2729 (1598 males and 1131 females) households living within six randomly selected villages (Table 1), two villages from each zone, as they were relatively homogenous according to the preliminary information obtained from the town's administrative office. Households were randomly sampled and the sample size (369) was determined according to Naing et al. [14]. To minimize errors arising from attrition, $10 \%$ of the sample size was added making the total sample to be 406 (244 males +162 females). Then, the proportional sample size method was applied to allocate the number of participant households to each village. Both sexes were encouraged to participate in the study. As the overall coverage of latrine and water service $(P)$ was unknown for the study area, the maximum national coverage of environmental sanitation with the main component of latrine coverage for Ethiopia $(60 \%)$ was considered at a $95 \%$ confidence interval $(Z)$ and a $5 \%$ degree of accuracy $(d)$. Individuals below 18 or above 80 years were excluded to gather data from matured active individuals.

2.3. Data Gathering Tools and Procedures. A recognizance survey was conducted before the actual study from 24 to 30 March 2018 to sketch out the overall status of latrine and water service coverage. WHO and UNICEF [15] were referred to in the preparation of certain portions of datagathering tools (observation, interview, and questionnaire) (See https://downloads.hindawi.com/journals/JEPH/2022/ 1203514.f1.docx file for details), but most of them were prepared by the authors based on the prevailing community 
TABLE 1: Study villages with their corresponding zones, target, and study households of Negele town during the study period (source: [13]).

\begin{tabular}{|c|c|c|c|c|c|c|c|c|}
\hline \multirow{3}{*}{ No. } & \multirow{3}{*}{ Zones } & \multirow{3}{*}{ Total households } & \multirow{3}{*}{ Selected villages } & \multirow{3}{*}{ Target households } & \multicolumn{4}{|c|}{ Sampled households $(n=406)$} \\
\hline & & & & & \multicolumn{2}{|c|}{ Frequency } & \multirow{2}{*}{ Total } & \multirow{2}{*}{$\%$} \\
\hline & & & & & Female & Male & & \\
\hline \multirow{2}{*}{1} & \multirow{2}{*}{ Central } & \multirow{2}{*}{1718} & Center of town & 590 & 34 & 54 & 88 & 21.67 \\
\hline & & & Central villages & 555 & 36 & 46 & 82 & 20.20 \\
\hline \multirow{2}{*}{2} & \multirow{2}{*}{ Eastern } & \multirow{2}{*}{1353} & Sheep site & 382 & 23 & 34 & 57 & 14.04 \\
\hline & & & Najat & 520 & 30 & 47 & 77 & 18.97 \\
\hline \multirow{2}{*}{3} & \multirow{2}{*}{ Western } & \multirow{2}{*}{1024} & Western Hindy & 417 & 24 & 38 & 62 & 15.27 \\
\hline & & & Mosque area & 265 & 15 & 25 & 40 & 9.85 \\
\hline Total & 3 & 4095 & 6 & 2729 & 162 & 244 & 406 & $100 \%$ \\
\hline
\end{tabular}

practices, the resources, and information accessible to the residents.

Latrines were observed for the presence of doors, roofs, hole covers, and water supply, while households were filling questionnaires according to the prepared observational checklist. Observations were made after obtaining the consent of the participants. Water fetching processes and various fields for open defecation sites were also observed.

A structured questionnaire was administered to gather data related to the households' sociodemographic characteristics, occupation, educational level, source of water, presence or absence of latrines, latrine doors, hole cover, and roof, where they defecate, and what problems they have faced in case they lacked a latrine, the presence of anybody who advised them to construct a latrine, whether they have a plan to construct a latrine shortly, the number of people using a latrine, the distance of the latrine from the kitchen, availability of water to clean the latrine and sewerage service to clean the latrine, measure $(s)$ taken when the latrine became full, source of water, treatment(s) undertaken for nontap water before drinking, and exposure to waterborne diseases. Interview was held with 40 purposively selected key informants (head of administration of the town, Kebele officials, water and health sector workers) regarding their sociodemographic attributes, presence of public latrines, factors affecting latrine and water service coverage, consequences of latrine shortage, presence of a plan and its target to improve the latrine and water service coverage of the town. As a key informant, the chief administrator of the town was also requested for any relevant additional information that he would like to add. Questions were prepared in English and translated into a local language (Afaan Oromo). Necessary orientation was provided to facilitate the process of filling out the questionnaire or responding to the interview questions. Questions were presented in the same wording and the same order to all participants.

2.4. Data Validity and Analysis. Before dispatching, questionnaires were tested on 25 purposely selected potential participants (19 males and 6 females) and the Cronbach's alpha score was found to be 0.799 and considered reliable according to Gliem and Gliem [16]. Collected data were checked for completeness, readability, or error. Descriptive and inferential analyses of quantitative data were performed employing Statistical Package for Social Science (SPSS; version 20) and results were presented in the form of frequency and percentage tables. A Chi-square test was conducted to see the association between various determinant factors and having latrine or tap water at $p \leq 0.05$ for statistical significance.

Narrative analysis was applied for qualitative data obtained via interviews, observation, and open-ended questionnaires. Data were repeatedly read and well understood, sorted by question/topic, and organized into coherent categories followed by interpretation.

\section{Results}

\subsection{Demographic Characteristics of the Participants}

3.1.1. Demographic Characteristics of Household Heads. Out of 406, 380 (93.6\%) households' heads properly filled and returned the questionnaires. Most of them were young (18-30 years), Muslims (86\%), and married (68\%) (Table 2).

Regarding educational status (Table 2), 118 (31.05\%) of the household heads had never attended formal education, whereas $186(51.6 \%)$ and $44(11.57 \%)$ of them had attended primary (grade 1--8) and secondary level (grade 9--12). Only $22(5.78 \%)$ of the participant household heads completed secondary school (grade 12). The majority of the participant household heads $(277 ; 59.7 \%)$ had up to 4 household members, whereas 108 (28.4\%) and $45(11.8 \%)$ of them had 5--10 and over 10 family size, respectively. The participant household heads have engaged in different types of jobs. They were predominantly farmers and merchants.

3.1.2. Demographic Characteristics of the Key Informants. Forty key informants with sociodemographic features indicated in Table 3 were properly interviewed. Most of the key informants were health workers, males, Muslims, married, diploma holders, and found within the age range of 18-40 years.

3.2. Latrine Coverage, Associated Facilities, and Usage. Only $45.3 \%$ of the household head participants indicated that they had latrines (Table 4). This was also confirmed by the authors' observation checklist data. Latrine coverage was lesser in the eastern zone of the town compared to central and western zones. Moreover, over $60 \%$ of the household 
TABLE 2: Demographic characteristics of heads of households that participated in the study $(n=380)$.

\begin{tabular}{|c|c|c|c|}
\hline Variable & & requency (\% & \\
\hline $\begin{array}{l}\text { Administration zones } \\
\text { Central } \\
\text { Eastern } \\
\text { Western } \\
\end{array}$ & $\begin{array}{l}\text { Female } \\
68(17.9) \\
45(11.8) \\
25(6.6) \\
\end{array}$ & $\begin{array}{c}\text { Male } \\
98(25.8) \\
81(21.3) \\
63(16.6) \\
\end{array}$ & $\begin{array}{c}\text { Overall } \\
166(43.7) \\
126(33.2) \\
88(23.1) \\
\end{array}$ \\
\hline $\begin{array}{l}\text { Age (years) } \\
18-30 \\
31-40 \\
41-80 \\
\end{array}$ & $\begin{array}{c}113(29.7) \\
55(14.5) \\
28(7.4) \\
\end{array}$ & $\begin{array}{c}75(19.7) \\
86(22.6) \\
23(6.1) \\
\end{array}$ & $\begin{array}{c}188(49.5) \\
141(37.1) \\
51(13.4) \\
\end{array}$ \\
\hline $\begin{array}{l}\text { Religion } \\
\text { Christian } \\
\text { Muslim } \\
\end{array}$ & $28(7.4)$ & & $\begin{array}{c}68(17.9) \\
312(82.1) \\
\end{array}$ \\
\hline $\begin{array}{l}\text { Educational status } \\
\text { No formal education } \\
\text { primary }(1-8) \\
\text { Secondary }(9-12) \\
\text { > Grade } 12\end{array}$ & $\begin{array}{c}41(10.8) \\
66(17.4) \\
19(5) \\
12(3.2) \\
\end{array}$ & $\begin{aligned} 77 & (20.3) \\
130 & (34.2) \\
25 & (6.6) \\
10 & (2.6)\end{aligned}$ & $\begin{array}{c}118(31.0) \\
196(51.6) \\
44(11.6) \\
22(5.8)\end{array}$ \\
\hline $\begin{array}{l}\text { Marital status } \\
\quad \text { Single } \\
\text { Married } \\
\text { Widow } \\
\text { Divorced } \\
\end{array}$ & $\begin{aligned} 27 & (7.1) \\
111 & (29.2) \\
0 & (0) \\
0 & (0)\end{aligned}$ & $\begin{aligned} 73 & (19.2) \\
149 & (39.2) \\
20 & (5.3) \\
0 & (0)\end{aligned}$ & $\begin{aligned} & 100(26.3) \\
& 260(68.4) \\
& 20(5.3) \\
& 0(0) \\
&\end{aligned}$ \\
\hline $\begin{array}{l}\text { Family size } \\
\quad 1-4 \\
5-10 \\
>10\end{array}$ & $\begin{array}{l}90(23.7) \\
26(6.8) \\
22(5.8) \\
\end{array}$ & $\begin{array}{c}137(36.1) \\
82(21.6) \\
23(6.1) \\
\end{array}$ & $\begin{array}{c}227(59.7) \\
108(28.5) \\
45(11.8) \\
\end{array}$ \\
\hline $\begin{array}{l}\text { Occupation } \\
\text { Farmer } \\
\text { Merchant } \\
\text { Government employee } \\
\text { Daily laborer } \\
\text { Other }\end{array}$ & $\begin{array}{c}59(15.5) \\
29(7.6) \\
28(7.4) \\
14(3.7) \\
8(2.1)\end{array}$ & $\begin{array}{c}117(30.8) \\
91(23.9) \\
13(3.4) \\
0 \\
21(5.5)\end{array}$ & $\begin{array}{l}176(46.3) \\
120(31.6) \\
41(10.8) \\
14(3.7) \\
29(7.6)\end{array}$ \\
\hline
\end{tabular}

head participants who had latrines indicated that a latrine was used by more than 5 people.

The majority of the available toilets were built without skill and technology and were found wanting in hygienic features like water supply, hole cover, roofs, doors (Figure 1), and the recommended distance from kitchen. Fifty-seven (33.1\%), 54 (31.4\%), 18 (10.5\%), and 43 (25\%) of household heads owning latrines said that their latrines are $3-5 \mathrm{~m}$, $2-3 \mathrm{~m}, 6 \mathrm{~m}$, and greater than $6 \mathrm{~m}$ away from kitchens, respectively. Data collected via an observation checklist revealed that $35.5 \%$ of households' latrine was located at a distance less than $6 \mathrm{~m}$ from the kitchen (Table 5) compared to the value (45.5\%) obtained via the questionnaire (Table 4).

More than half (52.3\%) of the households' heads replied that their latrine lacked roofs. Roughly, $50 \%$ of households' heads from the central and western zones indicated the presence of latrine roofs, whereas only $38 \%$ of eastern zone households' heads indicated the presence of latrine roofs. Fifty-three percent and $100 \%$ of the households' heads indicated the absence of latrine doors and hole cover, respectively (Table 4). Data on latrine roof, wall, and hole cover obtained via observation (Table 5) matched that of the questionnaire. The roofs were made from metal sheet, or wood covered with grass, plastic, or fertilizer sacks.
Similarly, the walls were made from fenced wood or plastic, or other material supported by wood (Figure 1) to prevent exposure of the users or entry of animals. Residents have usually been advised by health extension workers to put a sheet of metal or wood on the small hole of the latrine (called "hole cover" in this article) to protect flies, but none of them had done it.

The entire latrine-owned households' heads pointed out the lack of water to clean their latrines (also confirmed via observation) and sewerage services to clean their latrines when they became full. The lack of sewerage service to collect sewage when toilets become full had forced $70 \%$ and $30 \%$ of latrine owning household heads to dig new toilets and to drain their latrines into the environment, respectively (Table 4). Moreover, only 6 (3.48\%) latrine owning households' heads perceived their latrines as clean and good for health in contrast to $166(96.51 \%)$ that considered their latrines as unclean, usually dirty, and unhealthy. The authors' observations supported the latter as indicated in Figure 1.

3.3. Absence of Latrine and Associated Factors. Shortage of income and land was the reason cited by the majority of households' heads for not having latrines (Table 6). However, most of the interviewed key informants pointed out the low involvement of the administration of the town, low residents' awareness-/attitude-related issues as the main factor that had hindered the residents from building toilets (Table 7). Households latrine lacking were used to defecate in open fields $(56 ; 26.92 \%)$, in a bush $(54 ; 26 \%)$, in house compounds $(80 ; 38.5 \%)$, or in any place as needed $(18$; $8.65 \%$ ) (Table 6; Figure 2), as there were no public toilets as an alternate. Similarly, $100 \%$ and $43 \%$ of the key informants confirmed the absence of a public toilet and the existence of open defecation practices in the town, respectively (Table 7). The authors observed no public toilets in the town during the study. The practice of open defecation in different parts of the town was also noticed by the investigators during the field survey as a result of the shortage of private latrines together with the lack of public latrines (Figure 2). However, it was not possible to enumerate the people that practiced open defecation. The chief administrator of the town stressed that most of the houses that lacked latrines were built by people living in the surrounding rural areas and that the authorities found it difficult to create an awareness to avoid open defecation. About $50 \%$ of the households' heads replied that they had been advised to construct toilets either by health extension workers or by local leaders (Table 6).

Household heads lacking latrines expressed that they had been suffering from lack of safety, illness, pollution of living area, and moving out in the dark for defecation. Similarly, $35 \%$ and $23 \%$ of the key informants expressed the prevalence of waterborne health problems and environmental pollution in the town, respectively, due to lower latrine coverage (Table 7). However, $67 \%$ of household heads lacking toilets expressed that they had no plans to construct latrines in the near future due to income, land, or information constraints as expressed earlier. The authors also noticed that most of the houses in the town were built on small plots of land without following the plan of the town and allocating space 
Table 3: Demographic features of the key informants $(n=40)$.

\begin{tabular}{|c|c|c|c|c|}
\hline \multirow{2}{*}{ Variable } & \multicolumn{4}{|c|}{ Occupation } \\
\hline & Head of town administration & "Kebele" official & Water sector workers & Health workers \\
\hline \multicolumn{5}{|c|}{ 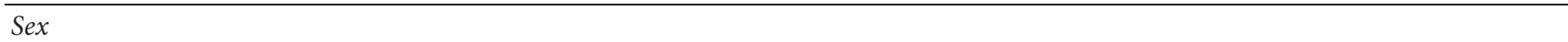 } \\
\hline Male & 8 & 5 & 3 & 18 \\
\hline Female & 1 & 0 & 0 & 5 \\
\hline \multicolumn{5}{|l|}{ Age (years) } \\
\hline $18-40$ & 7 & 3 & 3 & 21 \\
\hline $41-60$ & 2 & 2 & 0 & 2 \\
\hline $61-80$ & 0 & 0 & 0 & 0 \\
\hline \multicolumn{5}{|l|}{ Religion } \\
\hline Muslim & 7 & 5 & 3 & 14 \\
\hline Christian & 2 & 0 & 0 & 9 \\
\hline Other & 0 & 0 & 0 & 0 \\
\hline \multicolumn{5}{|l|}{ Marital status } \\
\hline Single & 3 & 1 & 0 & 8 \\
\hline Married & 6 & 4 & 3 & 15 \\
\hline Widow & 0 & 0 & 0 & 0 \\
\hline Divorce & 0 & 0 & 0 & 0 \\
\hline \multicolumn{5}{|c|}{ Educational status } \\
\hline Grade 9-10 & 3 & 4 & 0 & 0 \\
\hline Grade $11-12$ & 1 & 0 & 0 & 0 \\
\hline Certificate & 0 & 0 & 0 & 0 \\
\hline Diploma & 2 & 1 & 3 & 15 \\
\hline Degree & 3 & 0 & 0 & 8 \\
\hline Other & 0 & 0 & 0 & 0 \\
\hline
\end{tabular}

to construct latrines. The chief administrator of the town, a key informant, pointed out that the administration of the town had planned to build four public toilets by $2019 / 2020$. However, two-third of the key informants had no information regarding the plan of the administration of the town at all (Table 7).

3.4. Water Service Coverage and Associated Conditions. Only 29 household heads, all from the central zone of the town, replied that they had private tap water (Table 8). Few household heads said that they used to buy others' tap water expending much of their time lining up and their energy in carrying water for longer distances, whereas the majority of them replied that they were using unprotected water sources including ponds/rain and river water, particularly from Nano River traveling 3-5 km to the north of the town. These were also observed by the investigators (Figure 3), but it was not possible to count the number of people using each water source, so the numbers relied on the response of the household heads (Table 8). The area of the Nano River is mountainous making it somewhat difficult to fetch water from it. Moreover, using the river water directly for drinking could have created health problems as $72.6 \%$ of the household head participants replied that they directly use nontap water without boiling or chemical treatment (Table 8). Forty-five percent of the household heads said that they had no knowledge about the effect of impure water on health, but $51 \%$ of them said they or their families had contracted waterborne diseases.

Forty-five percent of the key informants expressed nonfunctioning public water pipes (Figure 4) as a factor for reduced water supply to the town. Public pipes were constructed in the town in 2010 at different places but became nonfunctional from 2013 to the time of the investigation.

The observational survey (Table 5) also revealed the presence of only a few private taps with infrequent and insufficient water. Moreover, all public pipes were not functioning during the investigation (Figure 4). Several key informants also mentioned low involvement of the administration, inadequate quantity of water from the source, and lack of storage tanks as contributing factors to the low water service coverage of the town. However, the chief administrator of the town, also a key informant, stressed the inadequacy of water as a major limiting factor for the provision of sufficient water to the town. The chief administrator also expressed that the town had planned to build water tankers and public water pipes across the town to raise its water supply coverage to about $70 \%$ by $2019 / 2020$. Only one-third of the key informants knew the existence of the plan although they were not sure about the planned percentage of water service coverage improvement as they put various ranges (Table 7).

3.5. Factors Associated with Having Latrine and Tap Water. The zonal sites, age, educational status, marital status, and family size of the households' head participants were found to be statically significantly associated with having latrines, $p<0.05$ (Table 9). The proportion of household head participants having latrines increased with the increase in age. More proportion of household head participants who had completed grade 12 possessed latrines compared to those with primary or secondary school education. However, a 
TABLE 4: Responses of households of Negele town $(n=380)$ on latrine coverage and associated facilities.

\begin{tabular}{|c|c|c|c|c|}
\hline \multirow{2}{*}{ Variable } & \multicolumn{3}{|c|}{ Frequency (\%) of participants per each zone } & \multirow{2}{*}{ Overall (\%) } \\
\hline & Center & East & West & \\
\hline \multicolumn{5}{|l|}{ Presence of own latrine* } \\
\hline Yes & $82(49.4)$ & $40(31.7)$ & $50(56.8)$ & $172(45.3)$ \\
\hline No & $84(50.6)$ & $86(68.3)$ & $38(43.2)$ & $208(54.7)$ \\
\hline \multicolumn{5}{|l|}{ Number of users of a latrine } \\
\hline $1-5$ & $33(40.2)$ & $12(30.0)$ & $20(40.0)$ & $65(37.8)$ \\
\hline $6-10$ & $30(36.6)$ & $8(20.0)$ & $20(40.0)$ & $58(33.7)$ \\
\hline Greater than 10 & $19(23.2)$ & $20(50)$ & $10(20.0)$ & $49(28.5)$ \\
\hline \multicolumn{5}{|l|}{ Distance of latrine from kitchen $(\mathrm{m})$} \\
\hline $2-3$ & $27(32.9)$ & $11(27.5)$ & $16(32.0)$ & $54(31.4)$ \\
\hline $3-5$ & $28(34.1)$ & $17(42.5)$ & $12(24.0)$ & $57(33.1)$ \\
\hline 6 & $9(11.0)$ & $5(12.5)$ & $4(8.0)$ & $18(10.5)$ \\
\hline Greater than 6 & $18(22.0)$ & $7(17.5)$ & $18(36.0)$ & $43(25.0)$ \\
\hline \multicolumn{5}{|l|}{ Presence of latrine roof } \\
\hline Yes & $41(50)$ & $15(37.5)$ & $26(52.0)$ & $82(47.7)$ \\
\hline No & $41(50)$ & $25(62.5)$ & $24(48.0)$ & $90(52.3)$ \\
\hline \multicolumn{5}{|l|}{ Presence of latrine door } \\
\hline Yes & $39(47.6)$ & $24(60.0)$ & $18(36.0)$ & $81(47.1)$ \\
\hline No & $43(52.4)$ & $16(40.0)$ & $32(64.0)$ & $91(52.9)$ \\
\hline \multicolumn{5}{|l|}{ Presence of latrine hole cover } \\
\hline Yes & $0(0)$ & $0(0)$ & $0(0)$ & $0(0)$ \\
\hline No & $82(100)$ & $40(100)$ & $50(100)$ & $172(100)$ \\
\hline \multicolumn{5}{|l|}{ Presence of water for cleaning latrine } \\
\hline Yes & $0(0)$ & $0(0)$ & $0(0)$ & $0(0)$ \\
\hline No & $82(100)$ & $40(1000$ & $50(100)$ & $172(100)$ \\
\hline \multicolumn{5}{|l|}{ Presence of sewerage to clean latrine } \\
\hline Yes & $0(0)$ & $0(0)$ & $0(0)$ & $0(0)$ \\
\hline No & $82(100)$ & $40(100)$ & $50(100)$ & $172(100)$ \\
\hline \multicolumn{5}{|c|}{ Whether latrine became full and overflown earlier or not } \\
\hline Yes & $36(43.9)$ & $9(22.5)$ & $12(24.0)$ & $57(33.1)$ \\
\hline No & $46(56.1)$ & $31(77.5)$ & $38(76.0)$ & $115(69.9)$ \\
\hline \multicolumn{5}{|l|}{ Measures taken when latrine was full } \\
\hline Digging new toilet & $65(79.3)$ & $20(50.0)$ & $36(72.0)$ & $121(70.3)$ \\
\hline Drainage to environment & $17(20.7)$ & $20(50.0)$ & $14(28.0)$ & $51(29.7)$ \\
\hline \multicolumn{5}{|l|}{ Perception of one's latrine } \\
\hline Clean and good for health & $5(6.1)$ & $0(0)$ & $12(0)$ & $6(3.5)$ \\
\hline Dirty and unsuitable for health & $77(93.9)$ & $40(100)$ & $49(98.0)$ & $166(96.5)$ \\
\hline
\end{tabular}

*The responses to the first question were given by all household heads who participated in the study, whereas the responses to other questions in the table were provided by only households that possessed private latrines

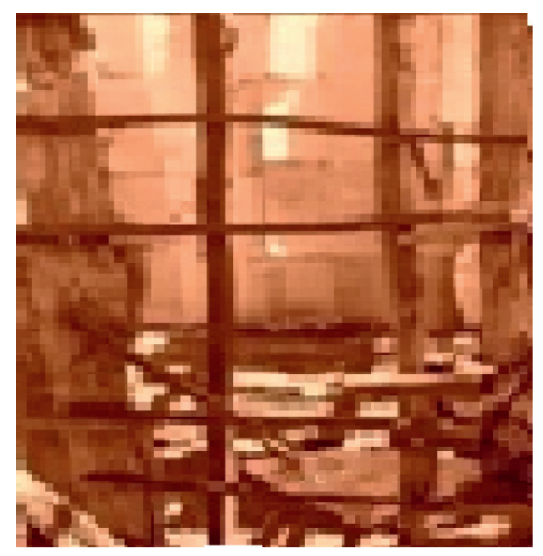

(a)

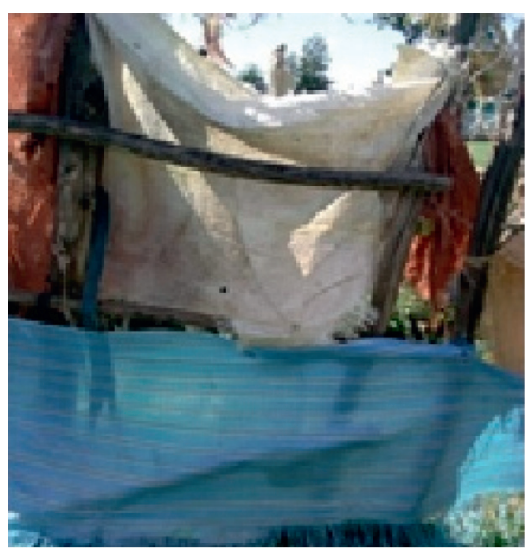

(b)

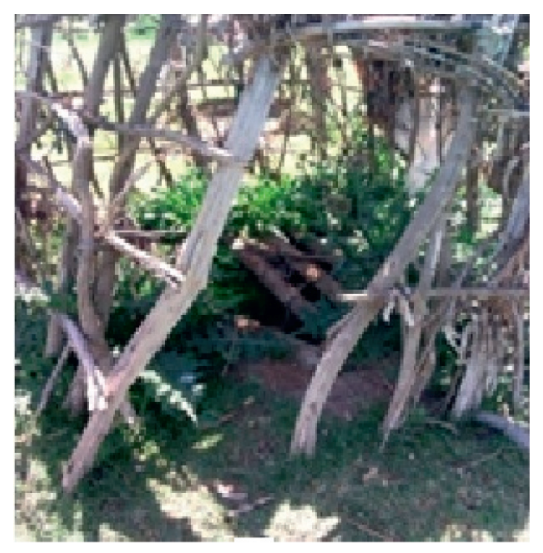

(c)

FIgURe 1: Appearances of some latrines of the participants of Negele town in 2018 (photo by Girma Deboch, 2018). (a) Incomplete wall with no roof, (b) surrounded by sacks to avoid exposure but with no roof, and (c) simple fence surrounded with no roof. 
TABLE 5: Observational checklist used to collect data from households $(n=380)$.

\begin{tabular}{|c|c|c|c|c|}
\hline No. & What was observed (present/absent if applicable) & Yes $(\%)$ & No $(\%)$ & Remark \\
\hline 1 & Household latrine & $172(45.3)$ & $208(54.7)$ & \multirow{6}{*}{ For households that had latrines } \\
\hline A & Latrine door & $81(47.1)$ & $91(52.9)$ & \\
\hline $\mathrm{B}$ & Latrine roof & $82(47.7)$ & $90(42.3)$ & \\
\hline $\mathrm{C}$ & Latrine hole cover & 0 & $172\{100)$ & \\
\hline $\mathrm{D}$ & Latrine water supply to clean & 0 & $172(100)$ & \\
\hline $\mathrm{E}$ & $\begin{array}{l}\text { Distance of latrine from kitchen } \\
\qquad<6 \mathrm{~m}\end{array}$ & $61(35.5)$ & $111(64.5)$ & \\
\hline 2 & Using public latrine & 0 & $172(100)$ & For households without latrine \\
\hline 3 & Practicing open defecation ${ }^{*}$ & & & Various parts of the town were observed \\
\hline 4 & Drinking-water source $(n=380)$ & & & \\
\hline A & Own private tap water & $29(7.6)$ & $351(92.4)$ & \\
\hline $\mathrm{B}$ & Others private tap water* & & & \multirow{5}{*}{ For households with no private tap water } \\
\hline $\mathrm{C}$ & Public tap water & 0 & $351(100)^{* *}$ & \\
\hline $\mathrm{D}$ & River* & & & \\
\hline $\mathrm{E}$ & Spring* & & & \\
\hline $\mathrm{F}$ & Pond/rain* & & & \\
\hline
\end{tabular}

Absence or presence was checked (Figures 1-3), but it was not possible to enumerate and calculate the percentages; ${ }^{* *}$ was implicated as no functional public taps were available in the town during the study.

TABLE 6: Defecation areas, plans, reasons for not having latrine, and problems faced by participants of Negele town $(n=208)$ who had no latrine before and during the study period.

\begin{tabular}{|c|c|c|c|c|}
\hline \multirow{2}{*}{ Variable } & \multicolumn{3}{|c|}{ Frequency (\%) of participants per zone } & \multirow{2}{*}{ Overall (\%) } \\
\hline & Center & East & West & \\
\hline \multicolumn{5}{|l|}{ Defecation areas } \\
\hline Open space & $20(23.8)$ & $26(30.2)$ & $10(26.3)$ & $56(26.9)$ \\
\hline Public toilet & $0(0)$ & $0(0)$ & $0(0)$ & $0(0)$ \\
\hline In bush & $16(19.0)$ & $29(33.7)$ & $9(23.7)$ & $54(26.0)$ \\
\hline In house compound & $42(50.0)$ & $22(25.6)$ & $16(42.1)$ & $80(38.5)$ \\
\hline Any place as needed & $6(7.2)$ & $9(10.5)$ & $3(7.9)$ & $18(8.6)$ \\
\hline \multicolumn{5}{|l|}{ Reasons for lack of latrine } \\
\hline Not knowing the importance of latrine & $0(0)$ & $0(0)$ & $0(0)$ & $0(0)$ \\
\hline Lack of enough land & $41(48.8)$ & $35(40.7)$ & $18(47.4)$ & $94(45.3)$ \\
\hline Lack of enough money & $36(42.9)$ & $37(43.0)$ & $12(31.6)$ & $85(40.8)$ \\
\hline Other & $7(8.3)$ & $14(16.3)$ & $8(21.0)$ & $29(13.9)$ \\
\hline \multicolumn{5}{|l|}{ Problems faced due to lack of latrine } \\
\hline Lack of safety & $21(25.0)$ & $25(29.1)$ & $14(36.8)$ & $60(28.8)$ \\
\hline Infectious disease & $12(12.3)$ & $31(36.0)$ & $9(23.7)$ & $52(25.0)$ \\
\hline Pollution of living area & $32(38.1)$ & $13(15.1)$ & $6(15.8)$ & $51(24.6)$ \\
\hline Moving out in the darkness & $19(22.6)$ & $17(19.8)$ & $9(23.7)$ & $45(21.6)$ \\
\hline \multicolumn{5}{|l|}{ A person advised constructing a latrine } \\
\hline Health extension & $17(20.2)$ & $27(31.4)$ & $18(47.4)$ & $62(29.8)$ \\
\hline Local leader & $23(27.4)$ & $13(15.1)$ & $5(13.1)$ & $41(19.7)$ \\
\hline Nobody & $44(52.4)$ & $46(53.5)$ & $15(39.5)$ & $105(50.5)$ \\
\hline \multicolumn{5}{|l|}{ Having plan to contact latrine } \\
\hline Yes & $34(40.5)$ & $25(29.1)$ & $9(23.7)$ & $68(32.7)$ \\
\hline No & $50(59.5)$ & $61(70.9)$ & $29(76.3)$ & $140(67.3)$ \\
\hline
\end{tabular}

higher proportion of household head participants with no formal education owned latrines. Marital status was also found to be significantly associated with having a latrine $\left(X^{2}=8.891 ; p \leq 0.05\right)$, where less proportion of married participants possessed latrines in contrast to single or widowed ones. Similarly, family size was significantly associated with having latrines $\left(X^{2}=14.23 ; p \leq 0.01\right)$, whereas more portions of participants with larger family sizes tend to possess latrines.
The study indicated the lack of significant association between having a latrine and sex, religion, or type of occupation, $p<0.05$ (Table 9).

Factors that showed significant association with having a latrine (zone, age, educational status, marital status, and family size) were also found to be significantly associated with having tap water (Table 10). Only participants from the central zone owned tap water. Similar to latrine ownership, the proportion of tap water ownership had increased with 
TABLE 7: Key informants' response regarding latrine and water service coverage.

\begin{tabular}{|c|c|c|c|}
\hline \multirow[t]{2}{*}{ Variables } & \multicolumn{2}{|c|}{$\begin{array}{l}\text { Frequency }(\%) \text { of } \\
\text { participants }\end{array}$} & \multirow[t]{2}{*}{ Overall (\%) } \\
\hline & Male & Female & \\
\hline \multicolumn{4}{|l|}{ Presence of public toilet } \\
\hline Yes & $0(0)$ & $0(0)$ & $0(0)$ \\
\hline No & $34(100)$ & $6(100)$ & $40(100)$ \\
\hline \multicolumn{4}{|l|}{ Effects of lack of public toilet } \\
\hline Suffering to use open defection & $15(44.1)$ & $2(33.3)$ & $17(42.5)$ \\
\hline Health problems related to waterborne diseases & $12(35.3)$ & $2(33.3)$ & $14(35.0)$ \\
\hline Environmental pollution & $7(20.6)$ & $2(33.3)$ & $9(22.5)$ \\
\hline \multicolumn{4}{|l|}{ Factors contributing to lack of latrine } \\
\hline Low involvement of administration & $11(32.4)$ & $2(33.3)$ & $13(32.5)$ \\
\hline Knowledge and attitude-related problems & $13(38.2)$ & $2(33.3)$ & $15(37.5)$ \\
\hline Shortage of income & $5(14.7)$ & $1(16.7)$ & $6(15.0)$ \\
\hline Lack of enough land & $3(8.7)$ & $0(0)$ & $3(7.5)$ \\
\hline Lack of follow-up & $2(6.0)$ & $1(1.7)$ & $3(7.5)$ \\
\hline \multicolumn{4}{|l|}{ Consequences of lack of latrine } \\
\hline Moving out in the dark for defecation & $18(52.9)$ & $3(50.0)$ & $21(52.5)$ \\
\hline Women and girls lack safety and privacy & $11(32.4)$ & $1(16.7)$ & $12(30.0)$ \\
\hline Suffering from bad odor when defecating around home & $5(14.7)$ & $2(33.3)$ & $7(17.5)$ \\
\hline \multicolumn{4}{|l|}{ Factors hindering water service coverage } \\
\hline Shortage of water from the source and lack of water tanks & $9(26.5)$ & $0(0)$ & $9(22.5)$ \\
\hline Nonfunctioning of public pipe & $14(41.2)$ & $4(66.7)$ & $18(45.0)$ \\
\hline Low involvement of administration & $8(23.5)$ & $2(33.3)$ & $10(25.0)$ \\
\hline Low income of the households & $3(8.8)$ & $0(0)$ & $3(7.5)$ \\
\hline \multicolumn{4}{|l|}{ The administration planned to improve latrine and tap water coverage } \\
\hline Yes & $11(32.4)$ & $2(33.3)$ & $13(32.5)$ \\
\hline No & $23(67.6)$ & $4(66.7)$ & $27(67.5)$ \\
\hline \multicolumn{4}{|c|}{ The extent to which the administration planned to raise latrine and tap water coverage } \\
\hline $26-50$ & $1(3.0)$ & $0(0)$ & $1(2.5)$ \\
\hline $51-80$ & $6(17.6)$ & $1(16.7)$ & $7(17.5)$ \\
\hline $81 \&$ above & $4(11.8)$ & $1(16.7)$ & $5(12.5)$ \\
\hline No response & $23(67.6)$ & $4(66.7)$ & $27(67.5)$ \\
\hline
\end{tabular}
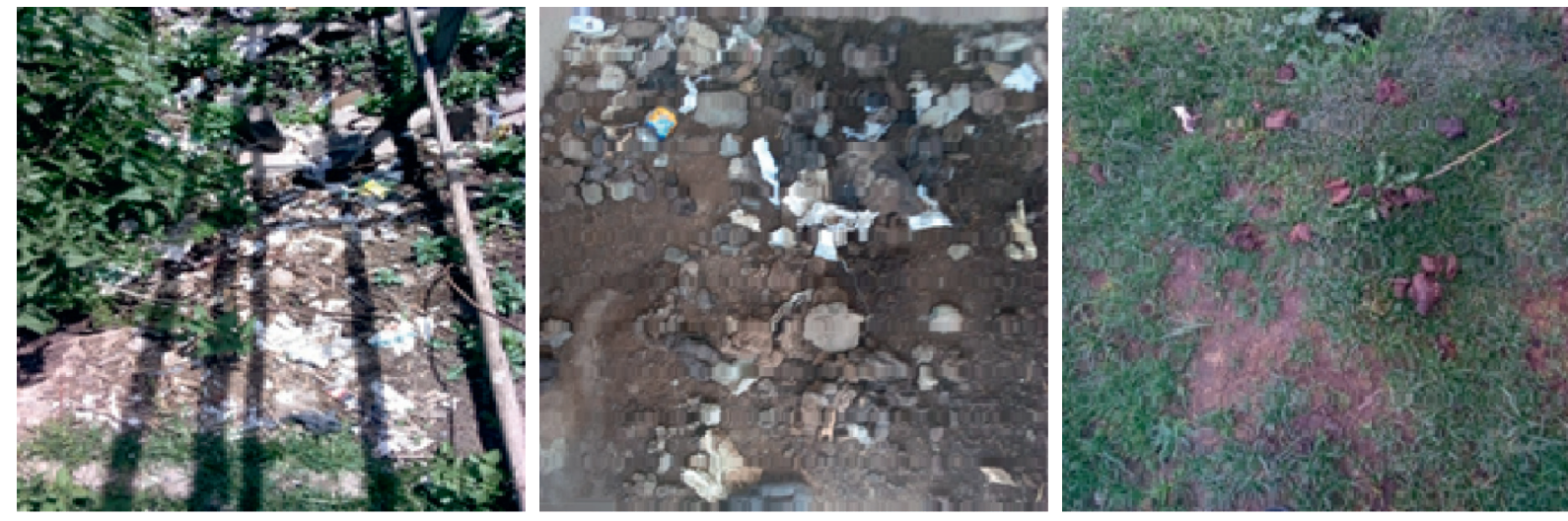

Figure 2: Some open defecation sites in Negele town (photo by Girma Deboch, 2018).

the increase in the age of participants. Educational status was also significantly associated with having tap water $\left(X^{2}=11.882, p \leq 0.01\right)$. Similar to latrine ownership, tap water ownership showed no significant association with sex, religion, or type of occupation of the participants as their $p$ values were $\geq 0.05$ (Table 10) .

\section{Discussion}

The overall latrine coverage of the town $(45.3 \%)$ was lower than that reported for some towns in Ethiopia including Dukem town (70.1\%; [17]) and Wolaita Sodo town (91\%; [9]), for Ilu Aba Bor Zone (88.2\%; [18]) and the overall 
TABLE 8: Water service coverage and related conditions of Negele town in 2018.

\begin{tabular}{|c|c|c|c|c|}
\hline \multirow{2}{*}{ Variable } & \multicolumn{3}{|c|}{ Frequency (\%) of participants per zone } & \multirow{2}{*}{ Overall (\%) } \\
\hline & General & Eastern & Western & \\
\hline \multicolumn{5}{|l|}{ Having a private tap water } \\
\hline Yes & $29(17.5)$ & $0(0)$ & $0(0)$ & $29(7.6)$ \\
\hline No & $137(82.5)$ & $126(100)$ & $88(100)$ & $351(92.4)$ \\
\hline \multicolumn{5}{|l|}{ Source of water if no one has tap water } \\
\hline Others' private tap water & $39(28.5)$ & $13(10.3)$ & $4(4.5)$ & $56(16.0)$ \\
\hline Nano River & $72(52.5)$ & $83(65.9)$ & $58(66.0)$ & $213(60.6)$ \\
\hline Pond and rain & $26(19.0)$ & $30(23.8)$ & $26(29.5)$ & $82(23.4)$ \\
\hline \multicolumn{5}{|l|}{ Using protected nontap water } \\
\hline Yes & 0 & 0 & 0 & $0(0)$ \\
\hline No & $137(100)$ & $126(100)$ & $88(100)$ & $351(100)$ \\
\hline \multicolumn{5}{|l|}{ Treating nontap water before drinking } \\
\hline Yes, using chemicals like "Bishangari ${ }^{a}$ or Wuhagar" & $15(11.0)$ & $3(2.4)$ & $3(3.4)$ & $21(6.0)$ \\
\hline Yes, boiling & $28(20.4)$ & $26(20.6)$ & $21(24.0)$ & $75(21.4)$ \\
\hline No & $94(68.6)$ & $97(77.0)$ & $64(72.6)$ & $255(72.6)$ \\
\hline \multicolumn{5}{|l|}{ Knowledge of the effect of impure water on health } \\
\hline Yes & $82(60.0)$ & $56(44.4)$ & $55(62.5)$ & $193(55.0)$ \\
\hline No & $55(40.0)$ & $70(55.6)$ & $33(37.5)$ & $158(45.0)$ \\
\hline \multicolumn{5}{|l|}{ Self or family member exposed to waterborne disease } \\
\hline Yes & $60(43.8)$ & $67(53.2)$ & $53(60.2)$ & $180(51.3)$ \\
\hline No & $77(56.2)$ & $59(46.8)$ & $35(39.8)$ & $171(48.7)$ \\
\hline
\end{tabular}

${ }^{a}$ Chlorine-based water treatment solution; ${ }^{b}$ a mixture of aluminum sulfate and calcium hypochlorite solution, both are available in local markets and people are advised and encouraged to use them to treat water at home.

Oromia region $(72.7 \%$; [19]) in which the town of study (Negele town) is found. The variations might be due to variations in awareness level and socio-economic status of the residents among others.

Besides lower coverage, the latrines were poor in hygiene. With a slight discrepancy in data collected via questionnaire-based participants' estimation and via measurement during observation, over one-third of the existing latrines were closer than the minimum recommended distance $(6 \mathrm{~m})$ from a kitchen according to WHO [5]. Thus, it is easy for the bad odor to reach living rooms and for flies to carry pathogens to the kitchen where food is prepared and kept. Similarly, in a different study, about $76 \%$ of participants from Nepal indicated that latrine distances from their homes were less than $6 \mathrm{~m}$ [20].

The absence of latrine roofs (52.3\%), doors (53\%), and hole covers $(100 \%)$ could promote the invasion and breeding of flies leading to disease dissemination. Even the existing roofs were made from torn plastic or other materials which cannot protect from flies or rain. Doors did not fit well and extended only up to half the height of the latrine merely to hide the users in some cases, implying the possibility of free invasion of flies. The participants had not accepted or practiced the usual advice of health extension workers to put a sheet of metal or wood (called hole cover in this article) on the small hole of the latrine to protect flies and reduce bad odor. This showed the necessity for further awareness creation and follow-ups. However, Yimam et al. [21] reported the presence of latrine hole cover in $47.6 \%$ of the latrines in Dembia town, northwestern Ethiopia.

Lack of cleaning water not only causes bad odor to reach homes but also hinders handwashing activity after using the toilet. Lack of sewerage service to collect sewage from filled latrines had forced the majority of the household heads (70\%) to dig new toilets which incur additional expenses. It had also forced some of the household heads (30\%) to drain the filled toilet to the environment which could affect human health and environmental sanitation. In many towns in Ethiopia, residents are not allowed to connect their latrines to wastewater channels as treatment is not practiced; rather, vehicles are available to draw out latrine waste and dispose of the waste somewhere else. In areas where such a facility is unavailable, full latrines need to be abandoned leading to land or money constraints to build new ones.

Perception of their latrine as clean, standardized, and good for health by a few participants (3.5\%) in the absence of good roofs, doors, and water for cleaning reflects their lack of good knowledge of sanitation, implying the need to raise public awareness and provide technical assistance in building latrines. In a previous study, Dagnew et al. [12] reported that $13 \%$ of the participants were using improved latrines in Chiro Zuria District, eastern Ethiopia.

Lack of enough land and money was raised by households as the key factor that hindered them from building their latrines, leading them to defecate in open fields, bush, and house compounds due to the lack of public toilet as an alternative. Similarly, households' capacity to finance the construction of home toilets was reported to be a fundamental factor in Wa Municipality of Ghana [22]. On the other hand, the key informants raised low involvement of the administration of the town, low residents' awareness-/attitude-related issues as the main factor that had hindered the residents from building their latrines. This shows that it is important to bring various sections of the society together to discuss and identify the key factors that hinder latrine construction to minimize or 


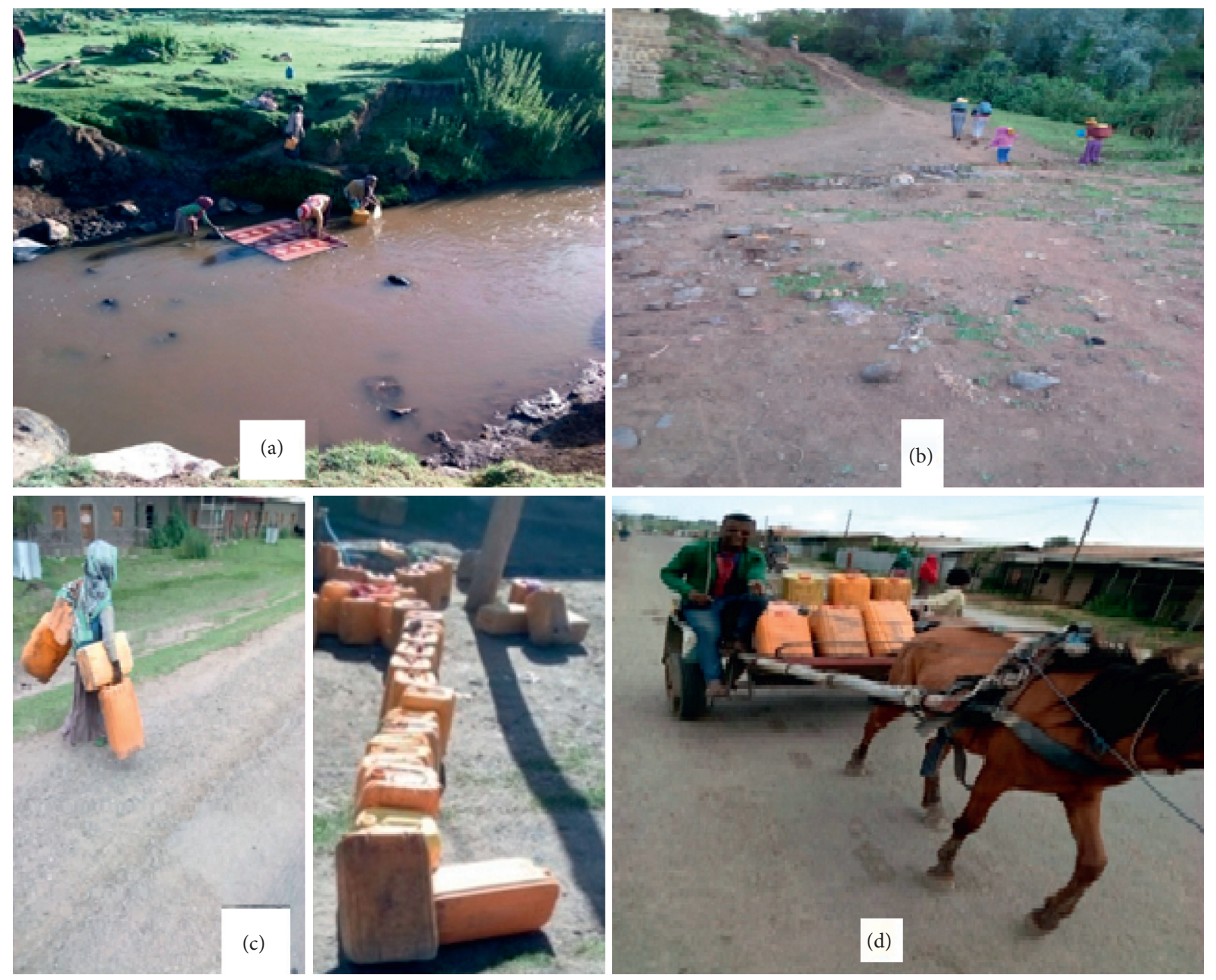

FIGURE 3: Fetching water from Nano River and transporting for longer distances on the back of people (a, b) and fetching water from the private tap with long waiting line (c) and transporting using a horse (d) (photo by Girma Deboch, 2018).

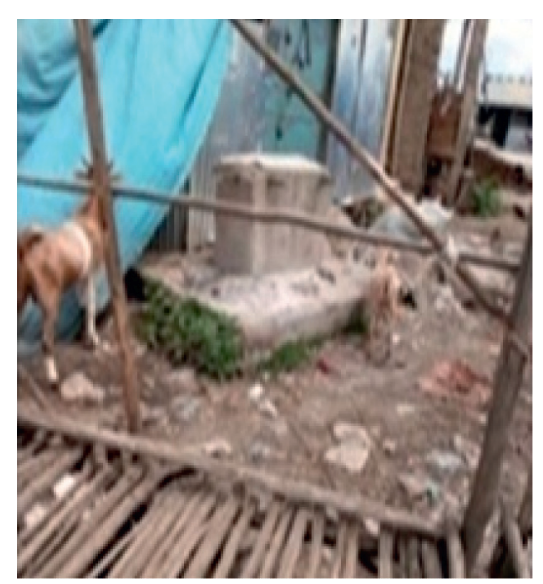

(a)

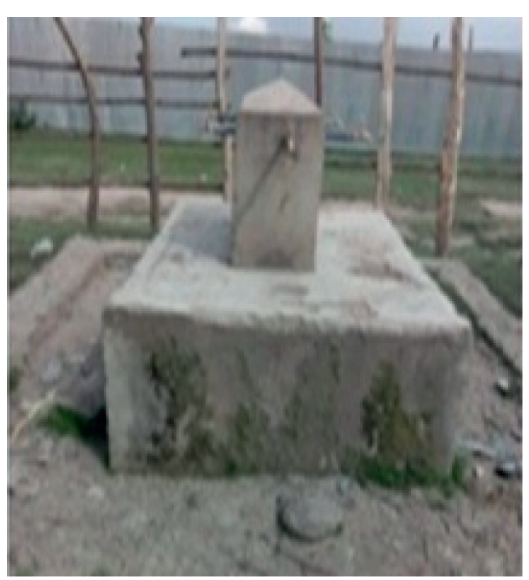

(b)

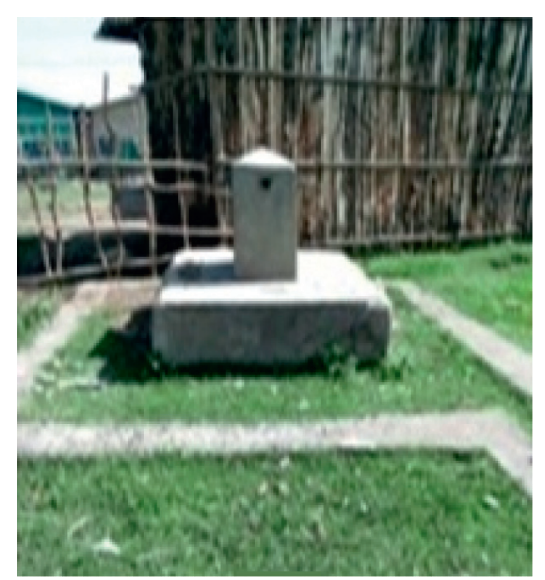

(c)

Figure 4: Nonfunctional public pipes $(\mathrm{a}-\mathrm{c})$ in the study area (photo by Girma Deboch, 2018).

avoid open defecation, as it influences environmental sanitation, human health, and psychology [23]. The administration of the town should be committed to providing enough land, searching for funding sources, constructing public toilets, and raising public awareness to solve the problem. Special attention should be given to public awareness creation and mobilization as $67 \%$ and $50 \%$ of households lacking latrines expressed that they had no plan and did not get 
TABLE 9: Association of having latrine and various factors $\left(X^{2}=\right.$ Chi-square $)$.

\begin{tabular}{|c|c|c|c|c|c|}
\hline \multirow[t]{2}{*}{ Factor } & \multirow[t]{2}{*}{ Description } & \multicolumn{2}{|c|}{$\begin{array}{l}\text { Have } \\
\text { latrine }\end{array}$} & \multirow[t]{2}{*}{$X^{2}$} & \multirow{2}{*}{$\begin{array}{c}P \\
\text { value }\end{array}$} \\
\hline & & Yes & No & & \\
\hline \multirow{3}{*}{ Zone } & Central & 82 & 84 & \multirow{3}{*}{15.180} & \multirow{3}{*}{$*$} \\
\hline & Eastern & 40 & 86 & & \\
\hline & Western & 50 & 38 & & \\
\hline \multirow{3}{*}{ Sex } & Male & 112 & 130 & \multirow{3}{*}{0.279} & \multirow{3}{*}{0.598} \\
\hline & Female & 60 & 78 & & \\
\hline & $18-40$ & 65 & 123 & & \\
\hline \multirow[t]{2}{*}{ Age } & $41-60$ & 79 & 62 & \multirow[t]{2}{*}{17.177} & \multirow[t]{2}{*}{ * } \\
\hline & $61-80$ & 28 & 23 & & \\
\hline \multirow{2}{*}{ Religion } & Muslim & 142 & 185 & \multirow{2}{*}{3.197} & \multirow{2}{*}{0.074} \\
\hline & Christian & 30 & 23 & & \\
\hline \multirow{4}{*}{$\begin{array}{l}\text { Educational } \\
\text { status }\end{array}$} & $\begin{array}{l}\text { No formal } \\
\text { education }\end{array}$ & 61 & 57 & \multirow{4}{*}{10.616} & \multirow{5}{*}{$* *$} \\
\hline & Primary (1-8) & 75 & 121 & & \\
\hline & Secondary (9-12) & 21 & 23 & & \\
\hline & $>$ Grade 12 & 15 & 7 & & \\
\hline \multirow{4}{*}{ Marital status } & Single & 52 & 48 & \multirow{4}{*}{8.891} & \\
\hline & Married & 106 & 154 & & \multirow{3}{*}{$* *$} \\
\hline & Widow & 14 & 6 & & \\
\hline & Divorced & 0 & 0 & & \\
\hline \multirow{3}{*}{ Family size } & $1-4$ & 85 & 142 & \multirow{3}{*}{14.23} & \multirow{3}{*}{$*$} \\
\hline & $5-10$ & 63 & 45 & & \\
\hline & $>10$ & 24 & 21 & & \\
\hline \multirow{5}{*}{ Occupation } & Farmer & 75 & 101 & \multirow{5}{*}{4.250} & \multirow{5}{*}{0.373} \\
\hline & Merchant & 51 & 69 & & \\
\hline & $\begin{array}{c}\text { Government } \\
\text { employee }\end{array}$ & 22 & 19 & & \\
\hline & Daily laborer & 7 & 7 & & \\
\hline & Other & 17 & 12 & & \\
\hline
\end{tabular}

*, ** Values show significant associations at $p \leq 0.01$ and $p \leq 0.05$, respectively.

advice, respectively, to build a latrine. Moreover, Yimam et al. [21] indicated that $88.6 \%$ of the participants who had latrines were advised to construct latrines by health extension or community health agent personnel in a northwestern Ethiopian town, Dembia.

Some open defecation sites were observed in the town during the study, but it was not possible to count households practicing it as many of them went out at night or early in the morning. No area was specifically designed for open defecation, but sloppy or deep eroded areas that are unsuitable for constructing homes were used for that purpose.

The plan of the administration of Negele town to build four public toilets at different parts of the town by 2019/2020 may be considered as a starting step to improve sanitation of the town. However, it seems to be insufficient. Moreover, our current information (December 2021) from the residents revealed that the administration of the town had built a single public toilet near a newly established bus station. The administration should focus on the constraints raised by the participants to bring better improvement in sanitary coverage. The administration should also control illegal house construction whose dwellers were found to commonly practice open defections due to lack of latrines.

The water service coverage $(7.64 \%)$ of the town was lower than other towns like Dukem (98.5\%; [17]) and
Wolaita Sodo (68\%; [9]), and a rural district in western Ethiopia (70\%; [24]) forcing most of the households to use unprotected Nano River water without heat or chemical treatment and thereby suffer from waterborne diseases. This implies that immediate action should be taken by the administration of the town and other concerned bodies to improve water service and create awareness of the community to boil or treat water using Wuha agar (chlorinebased water treatment solution) and Bishan gari (aluminum sulfate and calcium hypochlorite solution). These chemicals are available in the market and usually announced via mass media in different languages to be used to treat water at home to prevent waterborne diseases.

The administration of the town should work hard to effectively implement its plan of raising water service coverage to about $70 \%$ by $2019 / 2020$. However, the plan should be communicated as several key informants had no information about the plan which might hold true for other residents. The plan should also include maintaining nonfunctional public water pipes, developing various water sources including groundwater and springs, and establishing/expanding water purification and storage facilities. The plan should also target achieving Ethiopia's plan of providing safe water to all urban dwellers by 2020 [23]. The commitment of the administration of the town should also be added as key informants raised its lower involvement contributing to lower water service coverage of the town. Currently (December 2021), the residents of the town confirmed that the administration of the town totally failed to raise the water service coverage of the town according to the plan as it has done nothing to build water tanks, public water pipes, or develop new water sources at the town.

Generally, the latrine and water service coverage of the town was found to be much lower than the National Millennium Development Goal (MDG) of Ethiopia that targeted $100 \%$ improved hygiene and sanitation by 2015 [25], although the country managed to improve sanitation coverage from just $8 \%$ (1990) to $71 \%$ (2015) and reduce open defecation from 44.3 million (1990) to 28.3 million (2015) [19]. This further indicates that the town/country is not on track to extend safe water supply to $98 \%$ and $100 \%$ of rural and city dwellers, respectively, by 2020 via WASH [5] and to achieve sustainable development goals targets 6.1-universal access to safe water and 6.2-universal access to sanitation by 2030 [2]. However, some recent reports indicated that various nations are on track towards achieving United Nation's sustainable development goals (UN's SDG). Pereira and Marques [26] reported the convergence of low- and middle-income countries towards achieving the UN's SDG 6 , but at the expense of worsening the level of water crisis. Similarly, Pereira et al. [27] reported the convergence of the World Health Organization Member States regarding the United Nations' Sustainable Development Goal "Good health and well-being."

The zonal sites, age, educational status, marital status, and family size of the participants were statically significantly associated with having a latrine $(p<0.05)$. Although other sources of information like religious education, mass media, and health extension workers exist, the possession of 
TABLe 10: Association of having tap water and various factors $\left(X^{2}=\right.$ result of Chi-square $)$.

\begin{tabular}{|c|c|c|c|c|c|}
\hline Factor & Description & Having private tap water & Not having private tap water & $X^{2}$ & $P$ value \\
\hline \multirow{3}{*}{ Zone } & Central & 29 & 137 & \multirow{3}{*}{40.447} & \multirow{3}{*}{$*$} \\
\hline & Eastern & 0 & 126 & & \\
\hline & Western & 0 & 88 & & \\
\hline \multirow{3}{*}{ Sex } & Male & 19 & 223 & \multirow{3}{*}{0.046} & \multirow{3}{*}{0.831} \\
\hline & Female & 10 & 128 & & \\
\hline & $18-40$ & 8 & 180 & & \\
\hline \multirow[t]{2}{*}{ Age } & $41-60$ & 12 & 129 & \multirow[t]{2}{*}{10.452} & \multirow[t]{2}{*}{ * } \\
\hline & $61-80$ & 9 & 42 & & \\
\hline \multirow{3}{*}{ Religion } & Muslim & 27 & 300 & \multirow{3}{*}{1.300} & \multirow{3}{*}{0.254} \\
\hline & Christian & 2 & 51 & & \\
\hline & No formal education & 3 & 115 & & \\
\hline \multirow{3}{*}{ Educational status } & Primary $(1-8)$ & 17 & 179 & \multirow{3}{*}{11.882} & \multirow{3}{*}{$*$} \\
\hline & Secondary (9-12) & 8 & 36 & & \\
\hline & $>$ Grade 12 & 1 & 21 & & \\
\hline \multirow{4}{*}{ Marital status } & Single & 2 & 98 & \multirow{4}{*}{8.947} & \multirow{5}{*}{$* *$} \\
\hline & Married & 27 & 233 & & \\
\hline & Widow & 0 & 20 & & \\
\hline & Divorced & 0 & 0 & & \\
\hline \multirow{3}{*}{ Family size } & $1-4$ & 9 & 218 & \multirow{3}{*}{15.095} & \\
\hline & $5-10$ & 11 & 97 & & \multirow[t]{2}{*}{$*$} \\
\hline & $>10$ & 9 & 36 & & \\
\hline \multirow{5}{*}{ Occupation } & Farmer & 10 & 166 & \multirow{5}{*}{7.763} & \multirow{5}{*}{0.101} \\
\hline & Merchant & 8 & 112 & & \\
\hline & Governmental & 6 & 35 & & \\
\hline & Daily laborer & 3 & 11 & & \\
\hline & Other & 2 & 27 & & \\
\hline
\end{tabular}

$* * *$ Values show significant associations at $p \leq 0.01$ and $p \leq 0.05$, respectively.

latrines by a higher proportion of $\mathrm{g}$ household participants who completed grade 12 compared to primary or secondary level revealed the influence of education on sanitation awareness of the participants to construct their latrine. Educational status was also significantly associated with the use of improved sanitation in Ethiopia [3,9]. Similarly, individuals who had completed high school demonstrated better latrine utilization than those without formal education [11]. However, a higher proportion of participants of the current report with no formal education also possessed a latrine, which could be related to increased age as most individuals with no formal education are usually older and the study showed more latrine ownership among aged individuals. This could be due to having large house compound areas and building latrines through time by elder residents as found in many towns in the country. Recently, urban administrations gave residents small areas of land (as small as 75 square meters) to build homes due to a rapid increase in population size following rural to urban migration, and the land surrounding the towns are farmlands owned by farmers. However, it is common to buy such farmlands illegally and build homes there. In some cases, towns and urban areas lack clear boundaries. Building illegal houses without latrines or legal houses with a latrine at different parts of the town could have led to variation in latrine coverage across the zones.

Statistically significant association of family size with having a latrine could be due to the fact that larger families could have higher potential to construct their latrine as certain members could be employed generating income.
Regarding marital status, married individuals are expected to be independent of their family and build their own houses and latrines unless constrained by the shortage of funds or land described in the responses to the questionnaire.

In previous studies, "perception of building a toilet is expensive" was found to be associated with reduced toilet ownership among rural households in some eastern districts of Indonesia [28]. Education and household size were among the determinants of open defecation, which is related to the lack of latrine ownership in the Wa Municipality of Ghana [22]. Ajemu et al. [29] reported that promotion of Health Extension Workers, possession of private houses, and occupational status were more likely to be associated with latrine construction among some rural villages of Tigray region, northern Ethiopia.

Zones, age, educational status, marital status, and family size of the participants were statistically significantly associated with having tap water sources similar to latrine ownership. In Ethiopian towns, the central parts are usually the first to be established and get services like water and electricity. Old people that established the towns usually live in the central parts of towns where water services are better compared to other parts in most cases. Educational status can be related to income and information to get access to water service (tap water) as the data revealed that participants with no formal education were least in the proportion of owning tap water. The association between marital status or family size with having tap water could be due to the amount of daily water demand. Marriage increases the family size and larger families require more water and could 
have made a better effort to own tap water. Similarly, Gebremichael et al. [30] reported a significant association of households' drinking water sources with age, educational status, and family size in northwest Ethiopia. Earlier, Fortune and Sikod [31] indicated a significant association of distance of water sources and household size with the choice of drinking water source in Cameroon.

\section{Conclusion}

Latrine coverage of Negele town was low $(\approx 45 \%)$ due to shortage of land and funds, low involvement of administration and residents, and the expansion of illegal houses. The existing latrines lacked hygiene features. Low coverage of private toilets together with the absence of public toilets in the town has led to widespread open defecation practices with potential and practical negative impacts on the health of the community and sanitation of the environment. The water service coverage (tap water) of the town was also very low (below 10\%) due to inadequate water sources and the nonfunctionality of the existing water taps. The problems associated with lower latrine and water service coverage of the town seem to continue in the near future as most toiletlacking households had no plans to construct it and the administration of the town failed to implement its plan; constructed one of the four planned public toilets and did nothing in the case of water service as of December 2021. The zonal sites, age, educational status, marital status, and family size of the participants were statistically significantly associated with having latrine or tap water; $p<0.05$.

The administration of the town should provide land for latrine construction, construct a sufficient number of public toilets, should supply loans or search for aids as well as provide technical assistance for the construction of standardized private and public toilets. Searching for additional water sources like groundwater and maintaining nonfunctional and/or constructing new water pipes should be a point of focus of the administration of the town to improve the water service coverage of the town. Plans to improve latrine and water service coverage of the town should involve the residents and committed governmental/nongovernmental bodies taking the national and UN Sustainable Development Goals into account.

\section{Data Availability}

All data generated or analyzed during this study are included in this article.

\section{Ethical Approval}

The study proposal was reviewed and approved by the Ethics review committee of Madda Walabu University, School of Computational and Natural Sciences (Permission letter number: MWU/CNCS/40/2010). Institutional permission was obtained from the Negele Town Administrative Office before conducting the study (Permission letter number: 1397/32/7/2010). The number 2010 in the permission numbers indicates the Ethiopian calendar (EC), which lags ten years behind the Gregorian calendar (GC).

\section{Consent}

Participants participated in the study after providing their consent orally, and they were informed of opt-out consent. Their right to withdraw from research participation with no objection if they wish was also clearly indicated in the questionnaire. Although formal/written consent was not taken, the participants were informed of opt-out consent. Relevant individuals encountered during field observation were also informed of the purpose of the study and asked for information or taking photos after they ensured their willingness. They were ensured that the information collected would be kept confidential and used only for the research purpose.

\section{Conflicts of Interest}

The authors declare that they have no conflicts of interest.

\section{Authors' Contributions}

Diriba Temesgen identified the research problem, and Girma Deboch pretested the questionnaire and collected and analyzed the data. Both authors prepared the research design, interpreted the data, and wrote and approved the manuscript.

\section{Acknowledgments}

The research fund was entirely covered by Madda Walabu University, School of Graduate Studies, as regularly provided for graduate students but has no specific grant number. The authors would like to acknowledge Madda Walabu University for funding the study. They also forward their appreciation to all participants and authorities for their cooperation and for providing genuine information.

\section{Supplementary Materials}

The supplementary material contains a questionnaire, interview, and observation checklists employed for data collection. (Supplementary Materials)

\section{References}

[1] K. Tissington, Basic Sanitation in South Africa. A Guide to Legislation, Policy and Practice Socio-Economic Rights Institute of South Africa (SERI), Socio-Economic Rights Institute of South Africa, South Africa, 2011.

[2] United Nations, Sustainable Development Goal 6 Synthesis Report 2018 on Water and Sanitation, 2018 Sanitation, United Nations, New York, NY, USA, 2018.

[3] Y. Tafere, M. Woldie, and H. Assefa, "Investigations of latrine coverage and associated factors among Debretabor town, Amhara Region North west Ethiopia," International Journal of Public Health Science, vol. 5, no. 2, pp. 137-141, 2016. 
[4] UNICE and WHO, Progress On Household Drinking Water, Sanitation and Hygiene 2000-2017. Special Focus on Inequalities, UNICE and WHO, New York, NY, USA, 2019.

[5] WHO, Simple Pit Latrines. Fact Sheet 3.1 on Environmental Sanitation, World Health Organization, Geneva, Switzerland, 1996.

[6] WHO, Progress on Safe Treatment and Use of Waste Water. Piloting the Monitoring Methodology and Initial Findings for SDG Indicator 6.3.1, World Health Organization, Geneva, Switzerland, 2018.

[7] N. Tesfay and M. Biru M, "Three consecutive waves of cholera outbreak in Ethiopia (2015-2017): explanatory analysis," Ethiopian Journal of Health Sciences, vol. 30, no. 4, pp. 469-478, 2020.

[8] W. Awoke and S. Muche, "A cross-sectional study: latrine coverage and associated factors among rural communities in the District of Bahir Dar Zuria, Ethiopia," BMC Public Health, vol. 13, no. 1, pp. 1-6, 2013.

[9] A. Admassie and A. Debebe, "Estimating accesses to drinking water supply, sanitation and hygiene facilities in Wolitasodo town, southern Ethiopia, in Reference to National coverage," Journal of Environmental and Public Health, vol. 2016, Article ID 8141658, 9 pages, 2016.

[10] WASH (Water, sanitation, and hygiene), One WASH-the implementation of Ethiopia's National Program Eliminating Trachoma, 2016.

[11] R. A. Tessema, "Assessment of the implementation of community-led total sanitation hygiene, and associated factors in Diretiyara district, Eastern Ethiopia," PLoS One, vol. 12, no. 4, pp. 1-11, 2019.

[12] G. G. Dagnew, A. F. Abebaw, S. L. Wake, and A. G. Derso, "Assessment of latrine use and associated factors among rural community members in Chiro Zuria Woreda particularly in Kilinso and Nejebas Kebele," Journal of Microbial \& Biochemical Technology, vol. 11, no. 410, pp. 24-30, 2019.

[13] Negele Town Administration Office (NTOA), "Negele town population distribution by zones and villages," Unpublished document, 2018.

[14] L. Naing, T. Winn, and B. N. Rusli1, "Practical issues in calculating the sample size for prevalence studies," Archives of Orofacial Sciences, vol. 1, pp. 9-14, 2006.

[15] WHO and UNICEF, Core Questions on Drinking-Water and Sanitation for Household Surveys, WHO and UNICEF, Geneva, Switzerland, 2006.

[16] J. A. Gliem and R. R. Gliem, "Calculating, interpreting, and reporting Cronbach's alpha reliability Coefficient for likerttype scales," in Proceedings of the Midwest Research-toPractice Conference in Adult, Continuing, and Community Education, The Ohio State University, Columbus, OH, USA, October 2003.

[17] A. I Mohammed, L. I. Zungu, and M. E. Hoque, "Access to safe drinking water and availability of environmental sanitation facilities among Dukem town households in Ethiopia," Journal of Human Ecology, vol. 41, no. 2, pp. 131-138, 2014.

[18] D. Oljira and T. S. Berkessa, "Latrine use and determinant factors in Southwest Ethiopia," Journal of Epidemiology and Public Health Reviews, vol. 1, no. 6, pp. 1-5, 2016.

[19] UNICEF, "Progress on CLTSH in Ethiopia: findings from a national review," WASH Field Note FN/01/2017, vol. 1, no. 6, pp. 2-4, 2017.

[20] S. S Budhathoki, G. Shrestha, M. Singh, S. B. Bhattachan, N. Jha, and K. P. K. Paras, "Latrine coverage and its utilization in a rural village of Eastern Nepal: a community-based crosssectional study," BMC Research Notes, vol. 10, pp. 1-7, 2017.
[21] Y. T. Yimam, K. A. Gelaye, and D. H. Chercos, "Latrine utilization and associated factors among people living in rural areas of Denbia district, Northwest Ethiopia, a cross-sectional Study," Pan African Medical Journal, vol. 18, 2014.

[22] I. K. Osumanu, E. A. Kosoe, and F. Ategeeng, "Determinants of open defecation in the wa municipality of Ghana: empirical findings highlighting sociocultural and economic dynamics among households," Journal of Environmental and Public Health, vol. 2019, Article ID 3075840, 10 pages, 2019.

[23] I. Prahlad, Environmental Sanitation "Reflections from Practice" A Module for Community Health Practitioners: Society for Community Health Awareness, Research, and Action (SOCHARA), Environmental Sanitation Koramangala, Bangalore, India, 2015.

[24] F. D. Kibret and F. D. Tulu, "Challenges of potable water supply system in rural Ethiopia: the case of Gonji Kolela Woreda, West Gojjam zone, Ethiopia," Natural Resources and Conservation, vol. 2, no. 4, pp. 59-69, 2014.

[25] WHO, Africa./Ethiopia Response for Acute Watery Diarrhea Outbreak in Moyale Town, World Health Organization, Geneva, Switzerland, 2016.

[26] M. A. Pereira and R. C. Marques, "Sustainable water and sanitation for all: are we there yet?” Water Research, vol. 207, 2021.

[27] M. A. Pereira, A. S. Camanho, R. C. Marques, and J. R. Figueira, "The convergence of the World health organization member states regarding the United Nations' sustainable development goal 'good health and well-being," Omega, vol. 104, 2021.

[28] M. Hirai, A. Kelsey, K. Mattson, A. A. Cronin, S. Mukerji, and J. P. Graham, "Determinants of toilet ownership among rural households in six eastern districts of Indonesia," Journal of Water, Sanitation and Hygiene for Development, vol. 8, no. 3, pp. 533-545, 2018.

[29] K. F. Ajemu, A. A. Desta, A. A. Berhe, A. G. Woldegebriel, and N. M. Bezabih, "Latrine ownership and its determinants in rural villages of Tigray, northern Ethiopia: community-based cross-sectional study," Journal of Environmental and Public Health, vol. 2020, Article ID 2123652, 8 pages, 2020.

[30] S. G. Gebremichael, E. Yismaw, B. D. Tsegaw, and A. D. Shibeshi, "Determinants of water source use, quality of water, sanitation and hygiene perceptions among urban households in North-West Ethiopia: a cross-sectional study," PLoS One, vol. 16, no. 4, pp. 1-20, 2021.

[31] L. A. T. Fotue and F. Sikod, "Determinants of the households' choice of drinking water source in Cameroon," Journal of Sustainable Development in Africa, vol. 14, no. 3, pp. 86-97, 2012. 